\title{
DEVELOPMENT OF REPORTING DAMAGED ROAD CONDITION APPLICATION USING USER-CENTERED DESIGN METHODS CASE STUDY: PT. XYZ
}

\author{
Soleman \\ Department of Computer Science, Faculty of Information Technology \\ Budi Luhur University \\ Jakarta, Indonesia \\ solemediagrafik@gmail.com \\ Dendi Budiman \\ Department of Computer Science, Faculty of Information Technology \\ Budi Luhur University \\ Jakarta, Indonesia \\ dendi182@gmail.com
}

DOI: 10.31364/SCIRJ/v7.i10.2019.P1019717

http://dx.doi.org/10.31364/SCIRJ/v7.i10.2019.P1019717

\begin{abstract}
The road condition reporting application is a mobile-based application is a mobile based application that is used to report road conditions in Indonesia. In its use, there are several problems with the application, the system does not have a satisfy design, so that the application is difficult to use. Difficulties that are often faced are at the registration / login stage due to lack of information on the application, force closed and slow GPS (Global Positioning System) detection. To resolve this problem, needed to develop the Jalan Kita application. The method used in this study is User Centered Design (UCD). This study focuses on redesigning User Interface and User Experience $(U X)$ in applications using the UCD approach to problems based on user convenience, efficiency and usability. This research was conducted at the PT. XYZ, which has the tasks and functions of the operation and maintenance Jalan Kita application. This research aims to develop the Jalan Kita application, analyzing problems, gathering user needs, making design solutions to conducting design evaluations. by using the System Usability Scale (SUS) method for testing UI and Short Version of the User Experience Questionnaire (UEQ$S)$ for $U X$ testing. From the test results using SUS get a value of 82 (Excellent / B), and the UEQ-S test gets the overall 'Good'.
\end{abstract}

Keywords: Mobile Apps, Jalan Kita, User Cetered Design, road condition reporting, User Interface, User Experience.

\section{INTRODUCTION}

The Jalan Kita application is an application that is used to facilitate the participation of the public or road users in providing or reporting information related to damaged roads / road-supporting infrastructure in Indonesia on a mobile basis.
In use, there are problems on the Jalan Kita application are. One of them is user complaints about difficulties using the application. Applications that are running at this time there are some shortcomings, applications that are less informative so that users have difficulty using the application, other than that the results given by the user rating on Google Playstore shows user complaints of difficulties about the application. The problem that arises from the current system is that it does not currently meet user needs. Causes that affect deficiencies in the application are at the registration / login stage due to lack of information on the application and detection of GPS (Global Positioning System) which is slow so that the application closes itself (force closed).

The solution to the problem is the development of application user interfaces that focus on user needs. Seeing this the user centered design (UCD) method is more appropriate to use because user centered design is a user interface design method that focuses on user-centered needs. Based on research [2] the UCD method produces a better solution design in terms of user experience and better in terms of usability. Therefore, using the User Centered Design approach, application development can be done to suit the needs of users.

\section{A. System Development}

\section{THEORITICAL BASIS}

System development is defined as the process of extracting ideas, analysis, design, and implementation of a system. System development is the preparation of a new system to replace the old system as a whole or improve existing systems.

\section{B. User Centered Design (UCD)}

User Centered Design (UCD) is a design method that places the user at the center of a system design. UCD is used 
by developers and designers to ensure that the system created meets user needs. The concept of UCD is the user as the center of the system development process, and the goals / traits, context and environment of the system are all based on user experience [3].

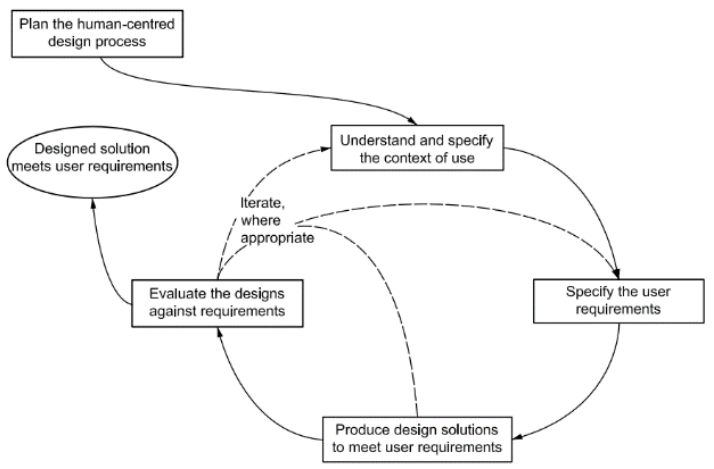

Figure 1: UCD Process (ISO 9241-210, 2010)

\section{System Usability Scale (SUS)}

System Usability Scale is a simple and concise questionnaire, consisting of 10 questions, and 5 answer scales for each question (Likert Skale). The Likert scale is based on limited choice questions on a scale of 5 or 7 . Some questionnaire items indicate a very positive response and vice versa.

SUS measurement is done by adding up the scores for each item. The score of each item is in the range of 0 to 4 . For items number 1, 3, 5, 7, and 9 (odd items) the item score is the result of user ratings for that item minus one. For items 2 , $4,6,8$, and 10 (even items) the score of an item is the result of 5 (five) minus the value of the user for that item. The total score of 10 items is then multiplied by the number 2.5 so as to produce a final score in the range $0-100$.

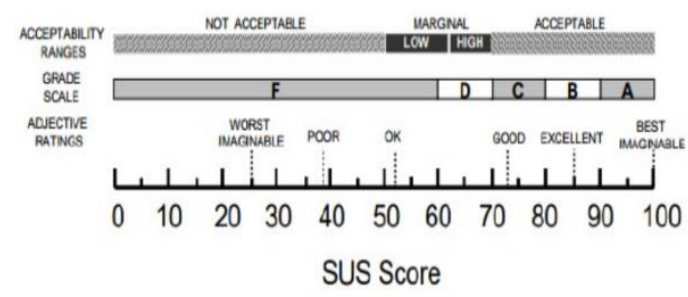

Figure 2: SUS Score (Brooke, 1996).

\section{Short Version of the User Experience Questionnaire(UEQ-S)}

User Experience Questionnaire (Laugwitz et al, 2008), including one of the questionnaires that can be used in usability tests to measure the level of User Experience of a product. UEQ is a questionnaire that is widely used to measure the user's subjective impression of the product user experience. UEQ-S is a short version of UEQ. From UEQ-S each scale remains represented and produces valid data. There are 6 scales with a total of 8 elements categorized based on measurement scales found in UEQ-S [6].

\section{E. Android}

Android is an operating system for Linux-based mobile devices. Android provides an open platform for developers to create their own applications that will be used for a variety of mobile devices.

\section{SYSTEM DESIGN AND APPLICATION \\ A. Research Methods}

In the research development of this damaged road reporting application, the author uses the user centered design method. The author also conducts literature studies on documents or journals related to the research conducted. The above method will be used to design a damaged road condition reporting application using the UCD approach, where this approach is used in order to analyze problems and design a model to improve the application for reporting damaged road conditions. The tool used is UML as a tool for making system modeling to be developed.

\section{B. Analysis Techniques}

The data analysis technique used in this research is descriptive data analysis. Sources of data for the purposes of data analysis are obtained at interviews, observations and documents related to research. The data is then processed, verified and made a model so that the data is easily understood by others.

\section{System Design Techniques}

The design technique used in this study uses the approach of the Object-Oriented Design method using Unified Modeling Language (UML). In the design process, the design techniques carried out are:

1. System business process design, modeled using Use Case Diagrams.

2. User interface design. In designing this interface design is made using the Java programming language.

\section{System Implementation Techniques}

Definition the implementation of the system in this study is the implementation based on the results of analysis and system design. The implementation technique is divided into three namely:

1. Implementation Environment. Includes hardware, software and networks used.

2. Database Implementation. Database implementation using PhpMyAdmin database software.

3. System Implementation. Implementation of the system using the Java programming language.

\section{E. Application Testing Techniques}

Application testing is needed to ensure that applications that have been or are being made can run in accordance with the expected functionality. Application developers or testers must prepare special sessions to test programs that have been made so that errors or deficiencies can be detected early and can be corrected as soon as possible.

To find out whether the application can be accepted or not by users, in this study application testing is divided into two parts, namely UI testing using the System Usabiliity Scale (SUS) and UX testing using the Short Version of the User Experience Questionanaire (UEQ-S).

\section{F. Research Steps}

In the development of reporting applications for damaged road conditions, the steps to be carried out include: the identification stage of the problem is carried out by conducting interviews, after identification of the problem is 
continued with the collection of data. Observation or make direct observations of business processes that exist in the object of research, studying literature studies related to the UCD method. From the results of data collection, the next step is to understand user needs, followed by gathering user needs. The results of gathering user needs, carried out the stage of making solutions in the form of design to meet user needs. From the results of the design solution an evaluation of the design is carried out using SUS for UI testing and UEQ-S for UX testing, if it does not meet user needs, iterates in the previous stage.

\section{G. Use Case Diagram}

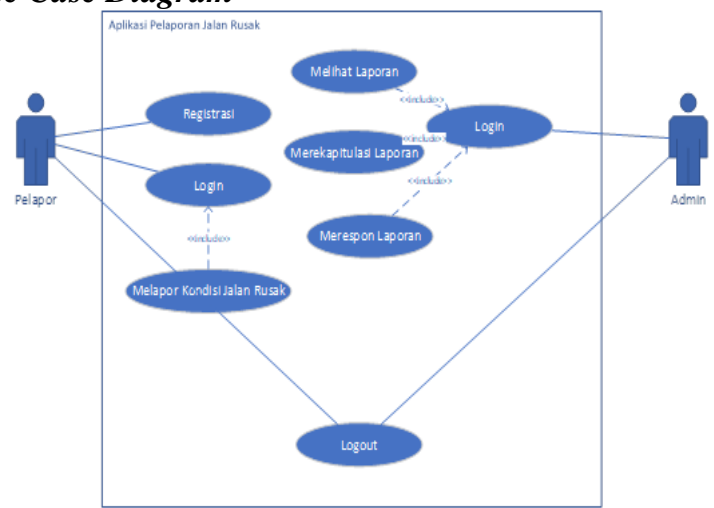

Figure 3: Use Case Diagram Reporting Damaged Road Condition Application

\section{RESULT AND DISCUSSION}

According to ISO 9241-210 (2010) in the design using user centered design there are 4 stages that must be carried out, namely:

1. Understand and determine the user's context;

2. Determine user needs;

3. The resulting design solutions;

4. Design evaluation of user needs.

\section{A. Understand Specifying the Context of Use}

The results of data collection in the Sub Directorate of Data Analysis and System Development, the characteristics of users reporting applications for damaged road conditions are as follows:

1. Application users are the community or road users;

2. The application can be used by men or women with any background;

3. Users use Android-based smartphones.

The purpose of this application is for road users to participate in organizing roads to submit complaints. Users are expected to play an active role in road repair by submitting complaints that occur in their environment so that the government can take action quickly.

\section{B. Specifying the User Requirements}

Information on the activities that users can do to the application for reporting damaged road conditions is obtained by analyzing existing applications and digging information from previous research. The results of identifying tasks performed by users and system characteristics are described in Tables 1 and 2.

Table 1: User Task List

\begin{tabular}{|c|l|}
\hline No. & \multicolumn{1}{|c|}{ User Task List } \\
\hline 1. & Registration \\
\hline 2. & Login \\
\hline 3. & Reporting road condition \\
\hline 4. & Take pictures to report \\
\hline 5. & $\begin{array}{l}\text { Fill in the report categories to be } \\
\text { reported }\end{array}$ \\
\hline 6. & Post a report \\
\hline 7. & Viewing report \\
\hline 8. & Viewing profile \\
\hline 9. & Logout \\
\hline
\end{tabular}

Table 2: System Characteristics

\begin{tabular}{|c|l|l|}
\hline No. & \multicolumn{1}{|c|}{$\begin{array}{c}\text { System } \\
\text { Characteristics }\end{array}$} & \\
\hline 1. & Hardware & $\begin{array}{l}\text { Smartphone with } \\
\text { RAM min. 1 GB }\end{array}$ \\
\hline 2. & Software & $\begin{array}{l}\text { Android OS with } \\
\text { minimal version } \\
5.0 \\
\text { Road condition } \\
\text { reporting } \\
\text { application }\end{array}$ \\
\hline 3. & Other completeness & $\begin{array}{l}\text { Turn on GPS } \\
\text { Using the internet } \\
\text { Allow camera } \\
\text { access }\end{array}$ \\
\hline
\end{tabular}

\section{The resulting design solutions}

The design of the solution design that will be made includes the application architecture design, application screen design, and interaction design.

\section{Architectural Design}

Navigation menus are designed according to user needs and functions that can be obtained in this application. Next is the design of the navigation structure:

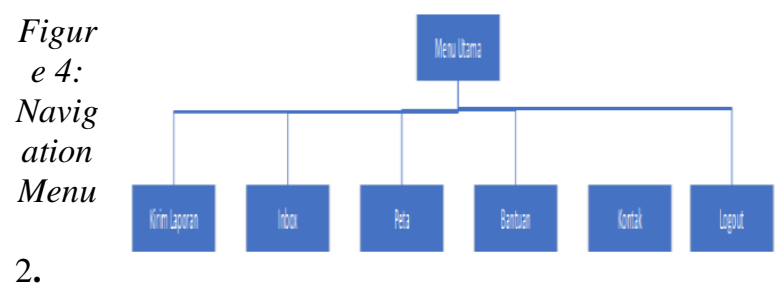

Design Interface

The screen design that will be used in the damaged road reporting application is as follows:

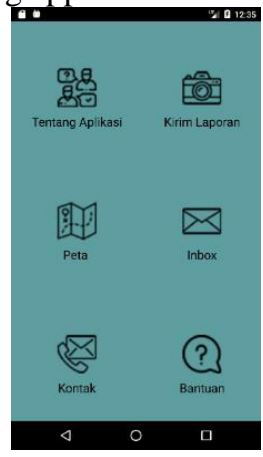

Figure 5: Design Interface Main Menu 


\section{c. Interaction Design}

The design of the interaction design is made in the form of user journey. User Journey is an important design tool for understanding products or services from the user's perspective. User journey illustrates the steps the user takes to achieve his goals. User journey has the function of demonstrating the way users interact with products, websites, or services at this time and demonstrating the possibility of users interacting with products, websites, or services. User journey reporting of damaged roads is shown in the table below:

Table 3: Interaction Design

\begin{tabular}{|l|ll|}
\hline User Flow & 1. & Register / Login \\
& 2. & Report Menu \\
& 3. & Take a Photo \\
& 4. & Select the report category \\
& 5. & Fill in the information \\
& 6. & Select the report button \\
\hline User Goals & 1. & Do reporting easily and quickly \\
& 2. & Successfully submit a report \\
\hline User & Pain & Registration difficulties \\
Points & 2. & The application takes too long to \\
& & get the location, so it takes time to \\
& 3. & Apport \\
& 1. & Registration / login made easy \\
& 2. & Speed up the application process \\
Opportunities & 3. & Make the application lighter \\
\hline
\end{tabular}

\section{Design evaluation of user needs}

After the solution design is made, then an evaluation of the results of the solution design is carried out. Evaluations are carried out using the System Usability Scale (SUS) test for UI testing and the Short Version of the User Experience Questionnaire (UEQ-S) for UX testing. The test results can be seen in point 4.5. System Testing.

\section{E. System Testing}

System testing are using two methods, namely UI testing using the System Usabiliity Scale (SUS) and UX testing using the Short Version of the User Experience Questionnaire (UEQ-S).

\section{a. System Usability Scale (SUS)}

After creating an application user interface (UI) design, it is necessary to test whether the application meets the usability element. Usability testing is carried out using the System Usability Scale (SUS). This SUS is one of the most popular usability testing tools. SUS was developed by John Brooke in 1986. This SUS is a usability scale that is reliable, popular, effective and inexpensive. [14]

The calculation rules used in SUS are as follows:

1. Each question numbered odd, the score of each question obtained from the user's score will be reduced 1. For example, statement number 3 is answered with "Agree", then the score for statement number 3 is: $4-1=3$

2. Each question even numbered, the final score obtained from the value of 5 minus the question score obtained from the user. For example, statement number 4 is answered with "Agree", then the score for statement number 4 is: $5-4=1$.

3. The SUS score is obtained from the sum of the scores for each question which is then multiplied by 2.5 . For example, the total score for respondent $\mathrm{A}$ is 25 , then the SUS score $=25 \times 2.5=62.5$.

Here are 10 questions from the System Usability Scale (SUS) which have been translated into Indonesian:

Table 4: System Usability Scale Testing Questions

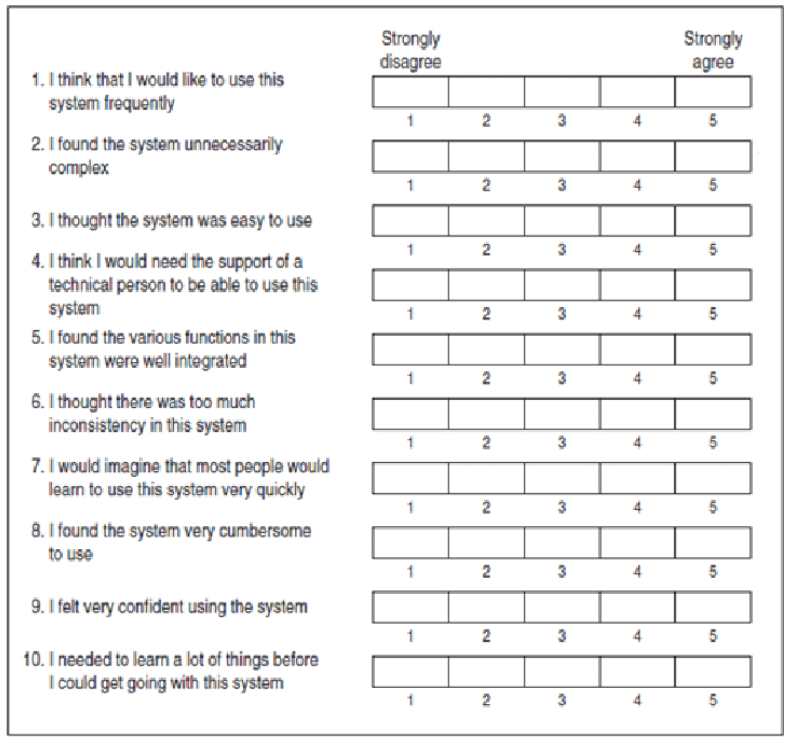

From the results of tests conducted using SUS with 20 respondents, get the following results:

Table 5: System Usability Scale Test Score

\begin{tabular}{|c|c|c|c|c|c|c|c|c|c|c|c|c|c|}
\hline \multirow{2}{*}{ No } & \multirow{2}{*}{ Respondents } & \multirow{2}{*}{ Age } & \multirow{2}{*}{ Gender } & \multicolumn{10}{|c|}{ Original Score } \\
\hline & & & & Q1 & Q2 & Q3 & Q4 & Q5 & Q6 & Q7 & Q8 & Q9 & Q10 \\
\hline 1 & Respondent 1 & 38 & Female & 4 & 2 & 4 & 1 & 5 & 3 & 4 & 1 & 4 & 2 \\
\hline 2 & Respondent 2 & 33 & Male & 5 & 1 & 4 & 1 & 5 & 1 & 4 & 3 & 5 & 2 \\
\hline 3 & Respondent 3 & 24 & Male & 5 & 1 & 5 & 1 & 4 & 1 & 4 & 1 & 5 & 3 \\
\hline 4 & Respondent 4 & 26 & Male & 5 & 1 & 5 & 1 & 3 & 2 & 5 & 1 & 5 & 1 \\
\hline 5 & Respondent 5 & 32 & Male & 5 & 1 & 4 & 1 & 5 & 1 & 4 & 2 & 5 & 2 \\
\hline 6 & Respondent 6 & 35 & Male & 5 & 1 & 5 & 1 & 4 & 2 & 3 & 2 & 5 & 1 \\
\hline 7 & Respondent 7 & 37 & Male & 5 & 2 & 5 & 1 & 4 & 3 & 3 & 1 & 5 & 1 \\
\hline 8 & Respondent 8 & 24 & Male & 5 & 1 & 5 & 1 & 5 & 3 & 4 & 1 & 5 & 2 \\
\hline 9 & Respondent 9 & 43 & Male & 5 & 1 & 4 & 1 & 5 & 3 & 3 & 2 & 4 & 4 \\
\hline 10 & Respondent 10 & 39 & Male & 5 & 1 & 4 & 2 & 4 & 2 & 4 & 2 & 5 & 2 \\
\hline 11 & Respondent 11 & 35 & Female & 5 & 1 & 5 & 1 & 4 & 3 & 4 & 2 & 5 & 2 \\
\hline 12 & Respondent 12 & 35 & Male & 5 & 1 & 4 & 3 & 3 & 2 & 4 & 2 & 4 & 3 \\
\hline 13 & Respondent 13 & 39 & Male & 5 & 2 & 4 & 1 & 4 & 2 & 3 & 2 & 5 & 3 \\
\hline 14 & Respondent 14 & 33 & Male & 5 & 1 & 5 & 3 & 5 & 2 & 4 & 1 & 4 & 3 \\
\hline 15 & \begin{tabular}{|l|} 
Respondent 15 \\
\end{tabular} & 29 & Male & 5 & 1 & 5 & 3 & 4 & 2 & 3 & 2 & 5 & 2 \\
\hline 16 & Respondent 16 & 53 & Male & 5 & 2 & 4 & 2 & 4 & 3 & 3 & 2 & 5 & 3 \\
\hline 17 & Respondent 17 & 43 & Male & 5 & 1 & 5 & 2 & 5 & 1 & 5 & 1 & 4 & 2 \\
\hline 18 & Respondent 18 & 57 & Male & 4 & 3 & 4 & 4 & 4 & 2 & 4 & 3 & 4 & 4 \\
\hline 19 & Respondent 19 & 43 & Male & 5 & 1 & 5 & 2 & 5 & 1 & 5 & 1 & 4 & 2 \\
\hline 20 & Respondent 20 & 36 & Male & 4 & 2 & 4 & 2 & 4 & 2 & 3 & 2 & 4 & 3 \\
\hline
\end{tabular}

Table 6: System Usability Scale Testing Result Score 


\begin{tabular}{|c|c|c|c|c|c|c|c|c|c|c|c|}
\hline \multicolumn{10}{|c|}{ Calculation Result Score } & \multirow{2}{*}{ Total } & Score \\
(Total $\times 2.5$ )
\end{tabular}

b.Short Version of the User Experiene Questionnaire (UEQ-S)

The Short Version of the User Experience Questionnaire includes one questionnaire that can be used in usability tests to measure the level of User Experience of a product. There are 6 scales with a total of 8 elements categorized based on measurement scales found in UEQ-S, namely:

Table 7: Item Short Version of the User Experience Questionnaire (UEQ-S)

\begin{tabular}{|c|c|l|}
\hline Negative & Positive & Scale \\
\hline obstructive & supportive & Pragmatic Quality \\
\hline complicated & easy & Pragmatic Quality \\
\hline inefficient & efficient & Pragmatic Quality \\
\hline confusing & clear & Pragmatic Quality \\
\hline boring & exciting & Hedonic Quality \\
\hline not interesting & interesting & Hedonic Quality \\
\hline conventional & inventive & Hedonic Quality \\
\hline usual & leading edge & Hedonic Quality \\
\hline
\end{tabular}

From the results of tests conducted using UEQ-S with 20 respondents, get the following results:

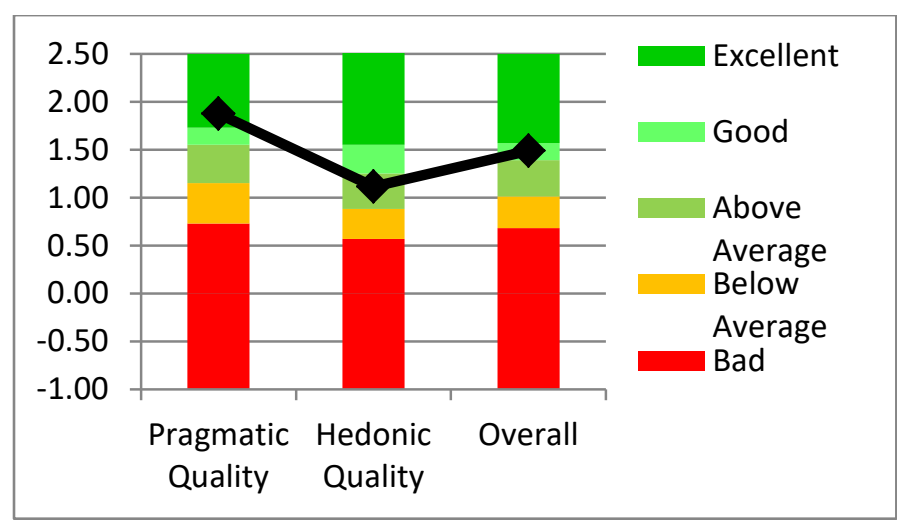

Figure 6: Graph of UEQ-S Test Results

Table 8: Remarks on UEQ-S Test Results

\begin{tabular}{|c|c|c|}
\hline Scale & Mean & $\begin{array}{c}\text { Comparisson to } \\
\text { benchmark }\end{array}$ \\
\hline $\begin{array}{c}\text { Pragmatic } \\
\text { Quality }\end{array}$ & 1,875 & Excellent \\
\hline $\begin{array}{c}\text { Hedonic } \\
\text { Quality }\end{array}$ & 1,1125 & Above Average \\
\hline Overall & 1,49 & Good \\
\hline
\end{tabular}

\section{CONCLUSION \& SUGGESTIONS}

\section{A. Conclusion}

Based on the results of the development of the reporting application of damaged road conditions using the User Centered Design method has been successfully created. From the test results using the System Usability Scale (SUS) and the Short Version of the User Experience Questionnaire (UEQ-S) that the application for reporting damaged road conditions is easy to use and acceptable. The score obtained by testing the user interface using the System Usability Scale (SUS) is 82 which means Acceptable or acceptable. And the results of user experience testing that has been done using the Short Version of the User Experience Questionnaire (UEQ-S) get a result of 1.49 (Good).

\section{B. Suggestion}

Based on the results of the study and the implications, the authors then provide suggestions relevant to the results of the study, including:

An evaluation of the road condition reporting application needs to be carried out, so that further developments can be made.

The use of this damaged road condition reporting application requires a set of policies or rules.

\section{REFERENCES}

[1] Abdillah, W. (2017), Metode Penelitian Terpadu Sistem Informasi. Yogyakarta: Penerbit ANDI

[2] Beltrán, B. A. G., López, L. G., \& Ortíz, A. R. (2016). User-Centered Design in Moodle Redesign for Mobile Use. (120), 1212-1224.

[3] Brooke, J., \& Weerdmeester, A. (1996). SUS-A quick and dirty usability scale". Usability evaluation in industry, B. Thomas and. Usability Evaluation in Industry, 189-194 SRC-GoogleScholar FG-0. Retrieved from https://books.google.co.in/books?hl=en\&lr=\&id=IfUsR mzAqvEC\&oi=fnd\&pg=PA189\&dq $=\mathrm{A}+$ _quick + and + dir

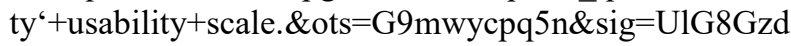
MU9UZQIh-nMF8cNm17Q0

[4] Danani, K., Bisht, P., Rautela, R., \& Bhattacharya, I. (2017). User Interface Design for Web And Mobile Devices. International Research Journal of Engineering and Technology, 4(6), 2395-56. Retrieved from https://irjet.net/archives/V4/i6/IRJET-V4I6398.pdf

[5] Díaz-Bossini, J. M., \& Moreno, L. (2013). Accessibility to mobile interfaces for older people. Procedia Computer Science, 27(Dsai 2013), 57-66. https://doi.org/10.1016/j.procs.2014.02.008

[6] Hinderks, A., Schrepp, M., \& Thomaschewski, J. (2018). A Benchmark for the Short Version of the User Experience Questionnaire. 373-377. https://doi.org/10.5220/0007188303730377

[7] Iqbal, M. W., Ahmad, N., \& Shahzad, S. K. (2017). Usability evaluation of adaptive features in smartphones. Procedia Computer Science, 112, 2185-2194. https://doi.org/10.1016/j.procs.2017.08.258 
[8] Joo, H. (2017). A study on understanding of UI and UX, and understanding of design according to user interface change. International Journal of Applied Engineering Research, 12(20), 9931-9935.

[9] Kar, S. (2014). Usability-Based User-Centered Design of Android Applications. 2(9).

[10] Laugwitz, B., Held, T., \& Schrepp, M. (2007). Preview Issue 4 / 2007. Lncs, 5298, 2007. Retrieved from http://citeseerx.ist.psu.edu/viewdoc/download?doi=10.1. $1.472 .3719 \&$ rep=rep $1 \&$ type $=$ pdf

[11]Lopes, A., Valentim, N., Moraes, B., Zilse, R., \& Conte, T. (2018). Applying user-centered techniques to analyze and design a mobile application. Journal of Software Engineering Research and Development, 6(1), 1-23. https://doi.org/10.1186/s40411-018-0049-1

[12] Mendapara, V. R., Ghodasara, Y. R., Poriya, G. S., \& Kamani, K. C. (2015). User-Centered Design ( UCD ) Approach for Designing of Platform Independent Applications in Smartphone. International Journal of Advanced Research in Computer and Communication Engineering, 4(12),

268-272. https://doi.org/10.17148/IJARCCE.2015.41262

[13] Noprisson, H., Husin, N., Utami, M., Rahayu, P., Sucahyo, Y. G., \& Sensuse, D. I. (2017). The use of a mixed method approach to evaluate m-Government implementation. 2016 International Conference on Information Technology Systems and Innovation, ICITSI 2016 - Proceedings, (February 2018). https://doi.org/10.1109/ICITSI.2016.7858195

[14] Sharfina, Z., \& Santoso, H. B. (2017). An Indonesian adaptation of the System Usability Scale (SUS). 2016 International Conference on Advanced Computer Science and Information Systems, ICACSIS 2016, 145148. https://doi.org/10.1109/ICACSIS.2016.7872776

[15] Sripathi, V., \& Sandru, V. (2013). Effective Usability Testing-Knowledge of User Centered Design is a Key Requirement. Ijetae.Com, 3(1), 627-635. Retrieved from http://www.ijetae.com/files/Volume3Issue1/IJETAE_01 13_102.pdf

[16] Sujan, J., Roy, S., Neumann, W. P., \& Fels, D. I. (2017). Human Interface and the Management of Information: Information, Knowledge and Interaction Design. 10273(Peterson 2013), 462-472. https://doi.org/10.1007/978-3-319-58521-5

[17]Zaina, L. A. M., \& Álvaro, A. (2015). A design methodology for user-centered innovation in the software development area. In Journal of Systems and Software (Vol. 110). https://doi.org/10.1016/j.jss.2015.08.029 